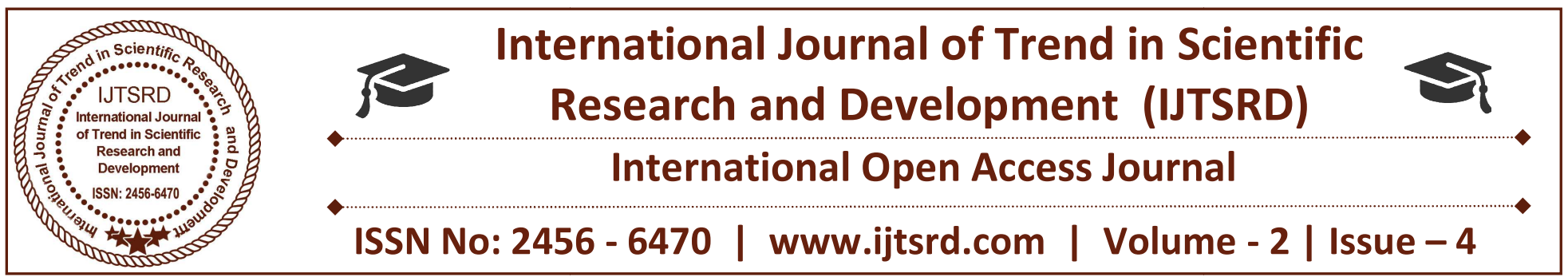

\title{
Power Management in Grid Isolated Hybrid Power System Incorporating RERs and BESS
}

\author{
Jaffer Amin Wani \\ M.Tech Scholar, Electrical Engineering Department, \\ Yamuna Institute of Engineering \& Technology, Gadhauli, Yamunanagar, Haryana, India
}

\begin{abstract}
The battery energy storage system (BESS) is one of the most commonly used method for smoothing the wind or solar power generation fluctuations. Such BESS based hybrid power systems require a suitable control strategy that can effectively regulate power output levels and battery state of charge (SOC). This paper presents the results of a wind/photovoltaic (PV)/BESS hybrid power system simulation analysis undertaken to improve the smoothing performance of wind/PV/BESS hybrid power generation and the effectiveness of battery SOC control. A smoothing control method for reducing wind/PV hybrid output power fluctuations and regulating battery SOC under the typical conditions is proposed. The effectiveness of these methods was verified using
\end{abstract} MATLAB/SIMULINK software.

Keywords: Adaptive smoothing control, battery energy storage station (BESS), solar power generation, state of charge (SOC), wind power generation

\section{INTRODUCTION}

In recent years, electricity generation by photovoltaic (PV) or wind power (WP) has received considerable attention worldwide. The battery energy storage system can provide flexible power management solutions that can improve the power quality of renewable-energy hybrid power generation systems. To that end, several control strategies and configurations for hybrid energy storage systems, such as a battery energy storage system [1]-[5], [13][19], a superconducting magnetic energy system (SMES) [6], a flywheel energy system (FES) [7], an

energy capacitor system (ECS) [8]-[12], and a fuel cell/electrolyzer hybrid system [20], [21], have been proposed to smooth wind power fluctuation or enhance power quality. Thanks to the rapid development of batteries, battery energy storage systems recently have begun to be utilized for multiple applications such as frequency regulation, grid stabilization, transmission loss reduction, diminished congestion, increased reliability, wind and solar energy smoothing, spinning reserve, peakshaving, load-leveling, uninterruptible power sources, grid services, electric vehicle (EV) charging stations, and others. These days, the issue of how power fluctuations in PV and wind power generation are to be smoothed has attracted widespread interest and attention. And even as this issue is being resolved, another one, that of the application of an energy storage system such as BESS, has arisen.

When using BESS to control PV and wind power fluctuations, there is a trade-off between battery effort and the degree of smoothness. That is, if one is willing to accept a less smooth output, the battery can be spared some effort. Thus far, although various effective BESS-based methods of smoothing power fluctuations in renewable power generation systems have been proposed [2], [3], [5], smoothing targets for grid-connected wind and PV farms generally have not been formulated. Smoothing control by way of power fluctuation rate limits, for such systems, has rarely even been discussed. The control strategies published in [1]-[5], [13]-[19], [25], [26] were formulated mainly for small-scale BESS-based smoothing; hence, they did not consider power allocation among several 
BESS. A suitable and effective control strategy for large-scale BESS, therefore, remains an urgent necessity.

In the present study, under the assumptions that the capacities of the WP and PV hybrid generation system (WPPVGS) and BESS had already been determined and that we do not have ability to adjust the WPPVGS output power, a large-scale BESS was used to smooth the WPPVGS output power fluctuation. More specifically, grid connected Wind/PV/BESS hybrid power generation system (Fig. 1) along with a state of charge (SOC)-based smoothing control strategy was utilized to instantaneously smoothen WP and PV power fluctuations. This was accomplished by modifying smoothed target outputs adaptively and making flexible use of feedback adjustments of battery SOC in real-time.

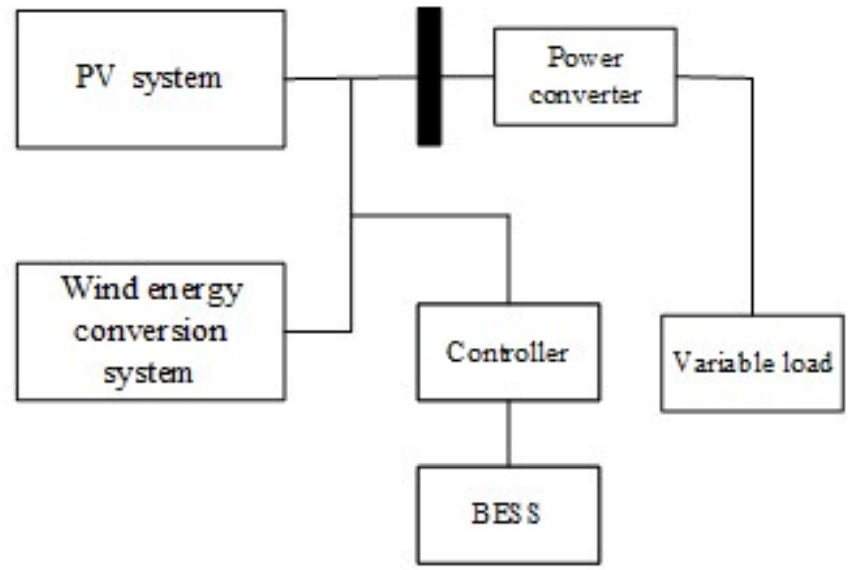

Fig. 1: Wind/PV/BESS hybrid power generation system

\section{MODELLING OF POWER SOURCES}

\section{A. PV energy conversion system}

The PV energy conversion system includes a PV module and a DC-DC boost converter. Depending on the state of the storage system, which it will be discussed in the energy management section, it can be operated under MPPT for maximum power extraction or off-MPPT for power balance as shown in Fig. 2. The power Ppv of the PV panel is expressed as:

$$
\mathrm{P}_{\mathrm{PV}}=\mathrm{VI}
$$

where, $V$ and $I$ are the voltage and current at the terminals of the PV module.

The MPPT algorithm follows the power variation

$\mathrm{dPpv}=\mathrm{dVI}+\mathrm{VdI}$
At the maximum power point, the power variation with respect of the voltage is

$\mathrm{dPpv} / \mathrm{dV}=\mathrm{I}+\mathrm{VdI} / \mathrm{dV}=0$

The MPPT algorithm is detailed in the flowchart of Fig. 3.

In case of power generation excess and no storage capacity in the battery system, the proposed energy management system (EMS) switches the PV controller from the MPPT mode to the off-MPPT mode in order to reduce the generated power and maintain a balanced power in the standalone system.

\section{B. Modelling of wind energy conversion system}

The wind turbine is emulated by a dynamometer, through the Turbine Emulator control function, to reproduce behavior under the power curve shown in Fig. 4. The Turbine Emulator control function set, shown in Fig. 4, is a package of control functions that can be activated in the four-quadrant dynamometer enabling the machine to emulate the operation of a real wind turbine with the power curve of Fig. 4. This function makes the permanent-magnet dc motor of the four-quadrant dynamometer faithfully reproduce the effect of wind on the bladed rotor of a small-scale wind turbine. The torque-speed characteristic at the shaft of the generator coupled to the four-quadrant dynamometer is the same as the one that is obtained when wind blows at a certain speed on the rotor of the wind turbine. The user has control over the wind speed by changing it through the Wind Speed slider, as shown in Fig. 4

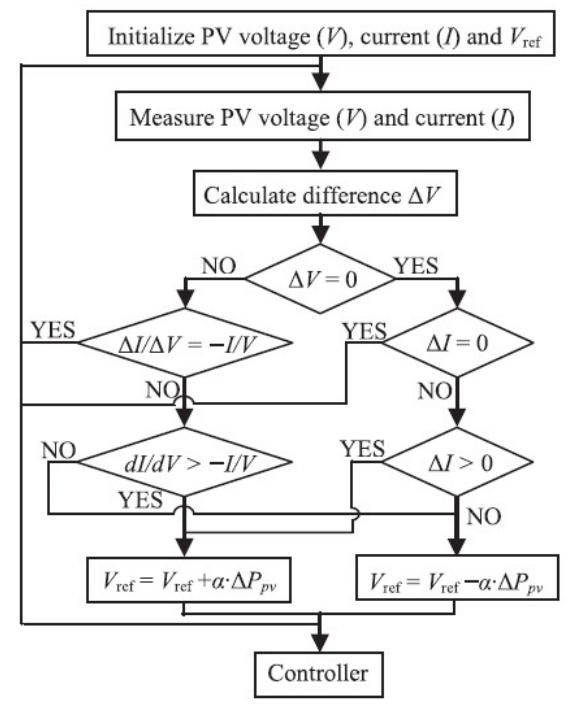

Fig. 3. MPPT algorithm flow chart 


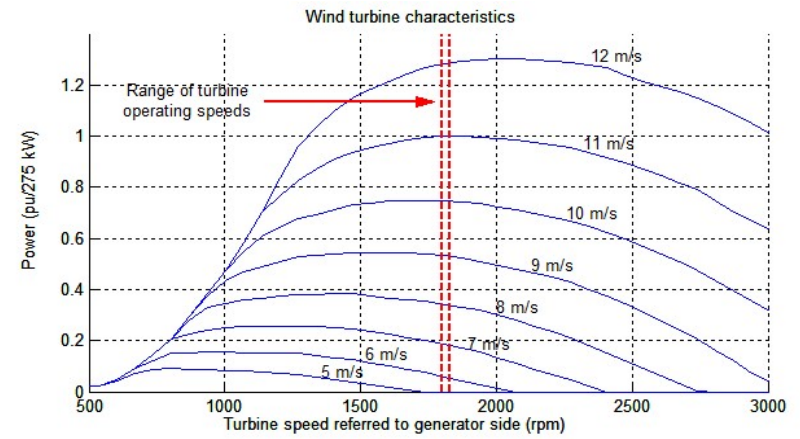

Fig. 2. Mechanical power versus turbine speed characteristics

The three-phase PMSG is modelled in the $(d, q)$ reference frame as:

isd $=-(R / L d) i \mathrm{sd}+(L q / L d) p \omega r$ isq $+1 / L d v \mathrm{sd}$

$i \mathrm{sq}=-(R / L q) i \mathrm{sq}+L d / L q) p \omega r i \mathrm{sd}-(1 / L q) p \omega r \phi v$ $+(1 / L q) v \mathrm{~s}(4)$

where, vd and vq are the d-q components of the stator voltage; isd and isq are the $\mathrm{d}-\mathrm{q}$ components of the stator current; $\phi \mathrm{v}$ is the permanent magnet magnetic flux linkage, $\mathrm{R}$ is the stator resistance; $\mathrm{Ld}$ and $\mathrm{Lq}$ are the stator winding $\mathrm{d}-\mathrm{q}$ components of the inductance and $\mathrm{p}$ is the number of pair poles.

The electromagnetic torque of the generator, by taking into consideration the symmetry in the generator $(\mathrm{Ld}=\mathrm{Lq})$, is given by

$\mathrm{Tg}=\mathrm{p} \phi \mathrm{v}$ isq

\section{Control of Hybrid power system}

\section{A. Control for WECS}

The WECS uses wind MPPT for extracting maximum available power from the wind turbine. The control for wind MPPT is shown in Fig. 3.

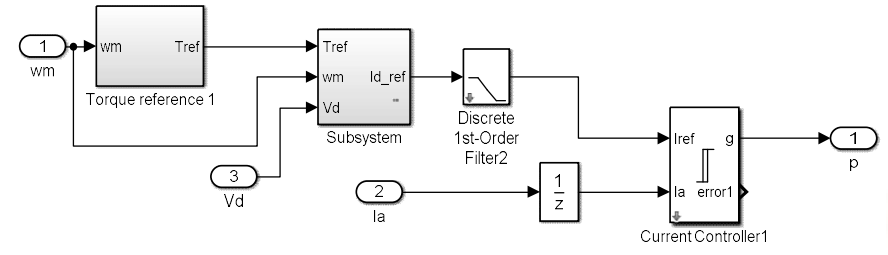

Fig. 3 Wind MPPT

First of all speed of the rotor of wind turbine is measured and d-axis reference current is calculated to compare with the measured $\mathrm{d}$-axis current. The difference of these two current is used to generate pulses for the converter.

\section{B. Control of BESS}

The BESS is used as a backup for both WECS and PV system. When there is any change in wind speed, solar irradiance or in load, BESS comes in to action and smooth the output of HRERs. Fig. 4 shows the control for BESS.

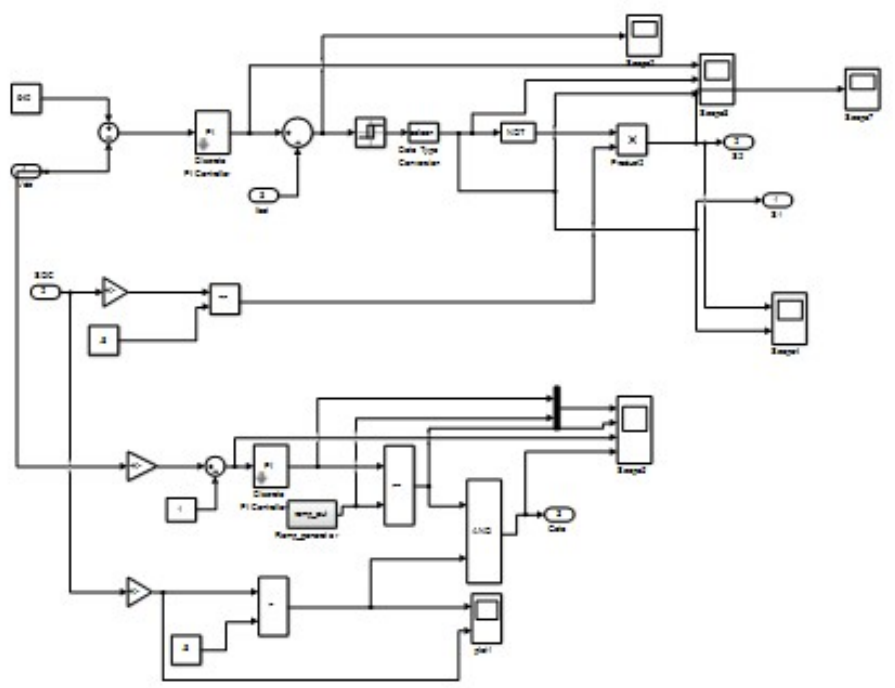

Fig. 4. Control for BESS 
International Journal of Trend in Scientific Research and Development (IJTSRD) ISSN: 2456-6470

\section{Simulations and results}

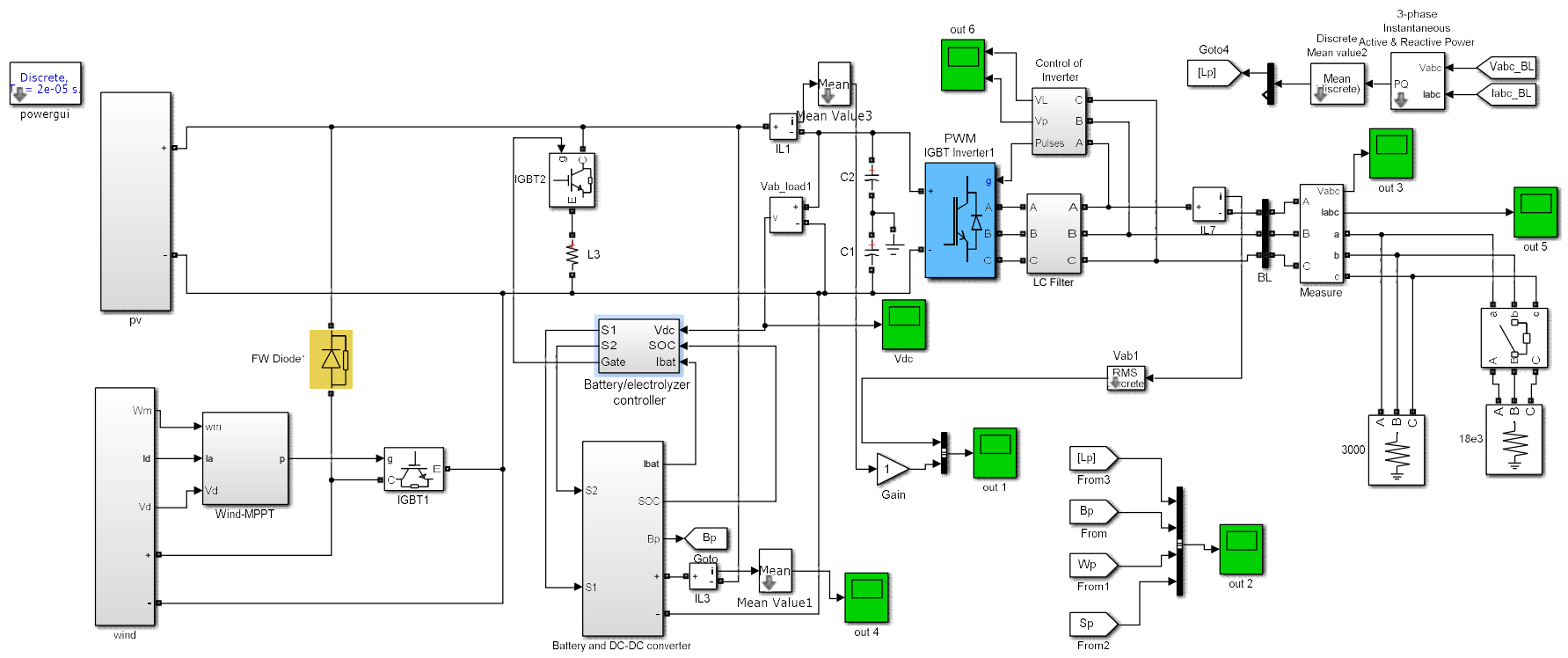

Fig. 5. Simulink model of HRERs based power system

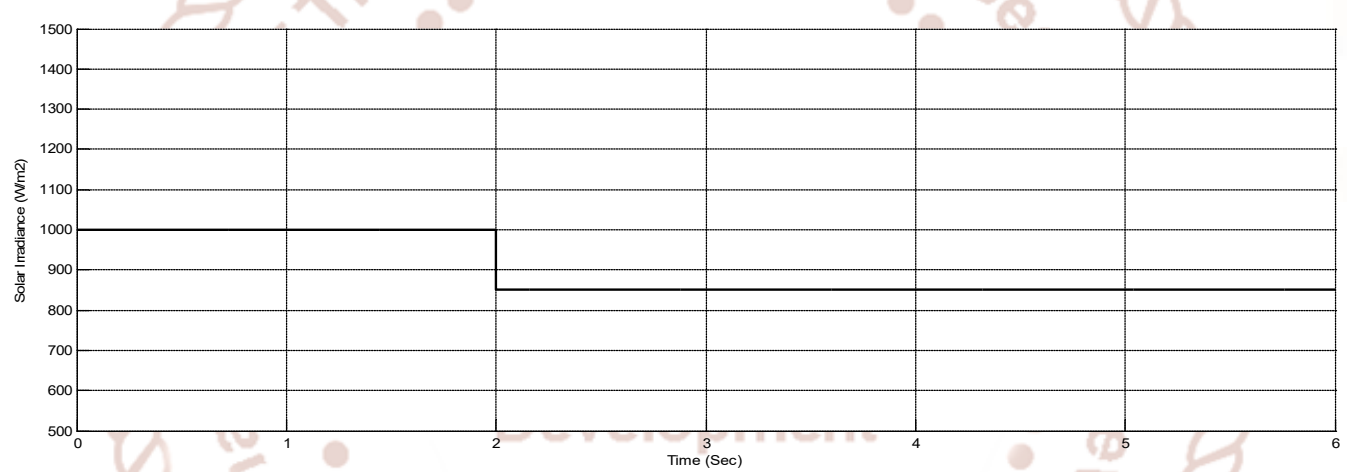

Fig. 6 Solar irradiance

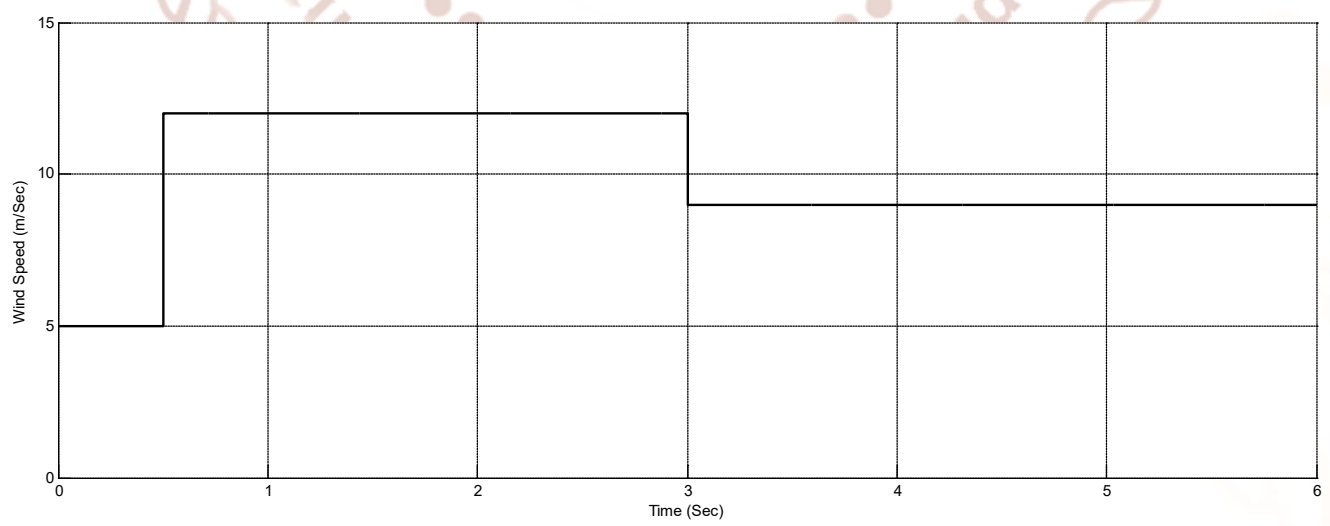

Fig. 7 Wind speed 


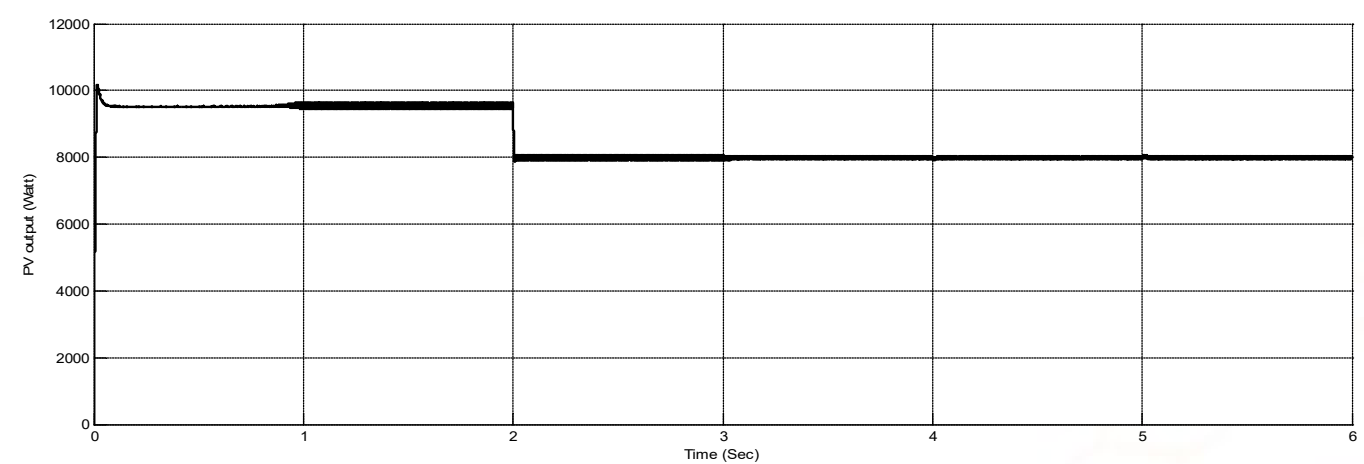

Fig. 8 Output power of PV system

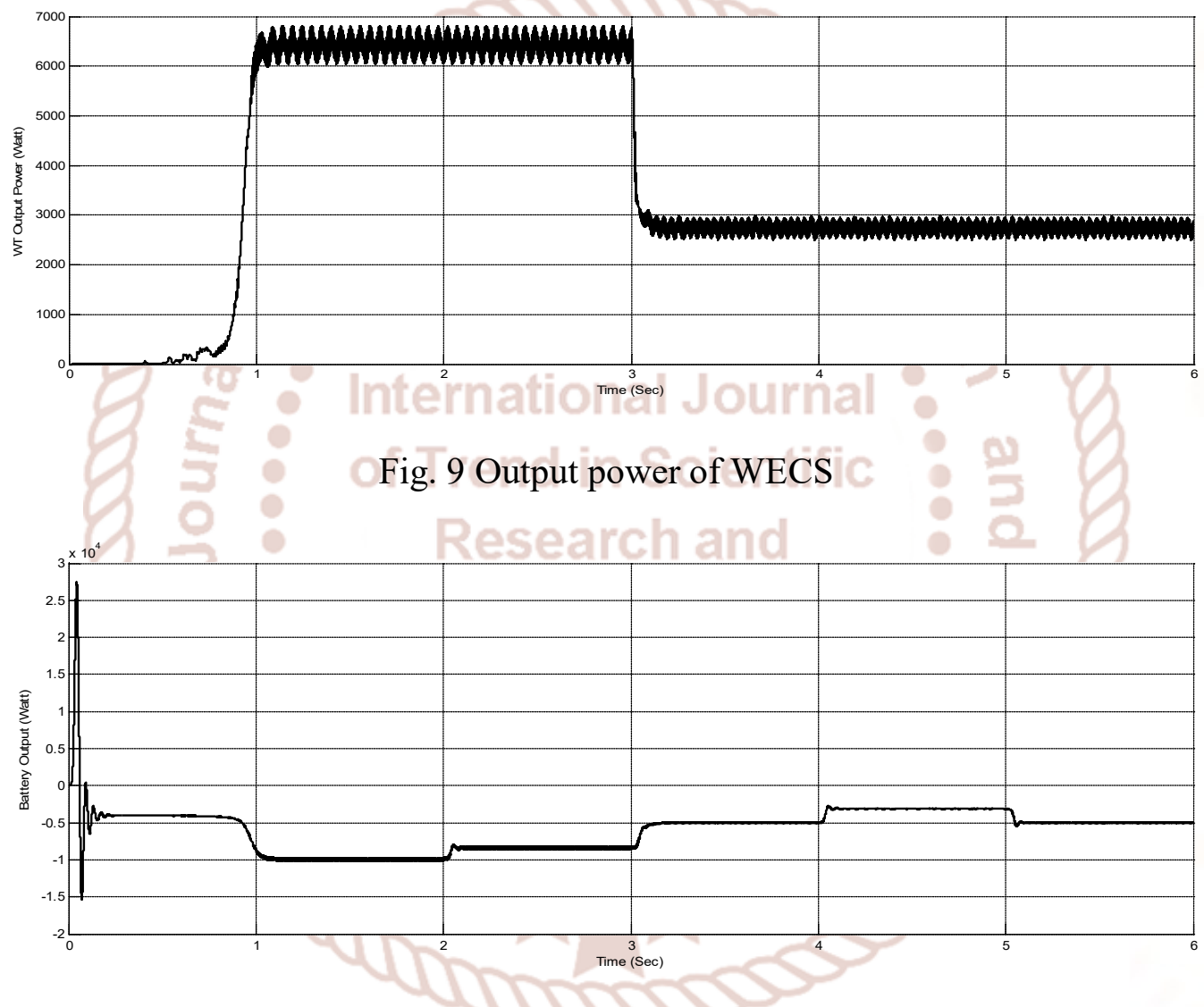

Fig. 9 Output power of BESS

The Simulink model built in MATLAB is modelled as shown in Fig. 5. The PV system is subjected with random solar irradiance as shown in Fig. 6. WECS is also subjected to variable wind speed shown in Fig.7. As these parameters varies the output of the WECs and PV system also vary. This can be shown in Fig. 8 and Fig. 9 respectively. As the output is not in our control. The excess power is stored in BESS and released upon demand when there is shortage in RERs output. This can be seen in Fig. 10. The BESS also responds to the change in demand as it is also vary continuously (Fig. 11).

\section{Conclusions}

The disadvantage of PV and wind power generation is their unstable power output, which can impact negatively on utility and micro-grid operations. One means of solving this problem is to integrate PVGS and WPGS with a BESS. For such hybrid generation systems, control strategies for efficient power dispatch need to be developed. Therefore, in this 
paper, a novel SOC-based control strategy for smoothing the output fluctuation. of a WP and PV hybrid generation system has been proposed. Additionally, the SOC feedback control strategy and the realtime power allocation method for timely regulation of battery power and energy are presented. Simulation results demonstrate that the proposed control strategy can manage BESS power and SOC within a specified target region while smoothing PVGS and WPGS outputs.

\section{REFERENCES}

1) W. Li and J. Géza, "Comparison of energy storage system technologies and configurations in a wind farm," in Proc. Power Electronics Specialists Conf. (PESC 2007), Jun. 2007, pp. 1280-1285.

2) M. E. Baran, S. Teleke, L. Anderson, A. Q. Huang, S. Bhattacharya, and S. Atcitty, "STATCOM with energy storage for smoothing intermittent wind farm power," in Proc. Power and Energy Soc. General Meeting - Conv. and Delivery of Elect. Energy in the 21st Century, Jul. 2008, pp. 1-6.

3) C. Abbey, K. Strunz, and G. Joós, “A knowledgebased approach for control of two-level energy storage for wind energy systems," IEEE Trans. Energy Convers., vol. 24, no. 2, pp. 539-547, Jun. 2009.

4) G. Koshimizu, T. Nanahara, K. Yoshimoto,H. Hasuike, and T. Shibata, "Subaru project: Application of energy storage for stabilizaion of wind power in power systems," in Proc. EAS 2005 Annu. Meeting Conf. Energy Storage Assoc., Toronto, Canada, 2005.

5) O. Krishan and Sathans, "Frequency regulation in a standalone wind-diesel hybrid power system using pitch-angle controller," in Proceedings of the 10th INDIACom; 2016 3rd International Conference on Computing for Sustainable Global Development, INDIACom 2016, 2016.

6) F. Zhou, G. Joos, C. Abbey, L. Jiao, and B. T. Ooi, "Use of large capacity SMES to improve the power quality and stability of wind farms," in Proc. IEEE Power Eng. Soc. General Meeting, Jun. 2004, pp. 2025-2030

7) R. Cardenas, R. Pena, G. Asher, and J. Clare, "Power smoothing in wind generation systems using a sensorless vector controlled induction machine driving a flywheel," IEEE Trans. Energy Convers., vol. 19, no. 1, pp. 206-216, Mar. 2004.

8) S. M. Muyeen, R. Takahashi, T. Murata, and J. Tamura, "Integration of an energy capacitor system with a variable-speed wind generator," IEEE Trans. Energy Convers., vol. 24, no. 3, pp. 740-749, Sep. 2009.

9) S. M. Muyeen, R. Takahashi, M. H. Ali, T. Murata, and J. Tamura "Transient stability augmentation of power system including wind farms by using ECS," IEEE Trans. Power Syst., vol. 23, no. 3, pp. 1179-1187, Aug. 2008.

10) H. Fakham and D. L. B. Francois, "Power control design of a battery charger in a hybrid active PV generator for load-following applications," IEEE Trans. Ind. Electron., vol. 58, no. 1, pp. 85-94, Jan. 2011.

11) R. Kamel, A. Chaouachi, and K. Nagasaka, "Wind power smoothing using fuzzy logic pitch controller and energy capacitor system for improvement micro-grid performance in islanding mode," Energy, vol. 35, pp. 2119-2129, 2010. 